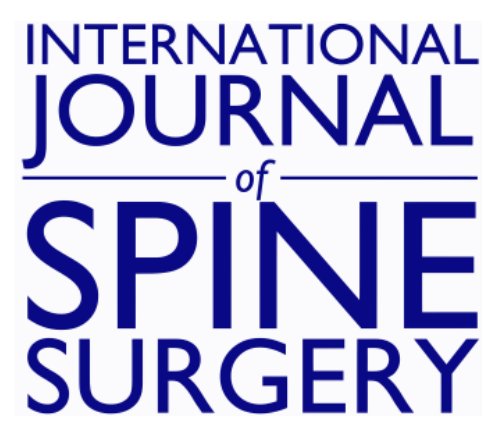

\title{
Success Rate of Brace Treatment for Juvenile-Onset Idiopathic Scoliosis up to Skeletal Maturity
}

TAHER BABAEE, MOJTABA KAMYAB, MOHAMMAD SALEH GANJAVIAN, NAEIMEH ROUHANI and JAMES JARVIS

Int J Spine Surg 2020, 14 (5) 824-831

doi: https://doi.org/10.14444/7117

http://ijssurgery.com/content/14/5/824

This information is current as of April 26, 2023.

Email Alerts Receive free email-alerts when new articles cite this article. Sign up at: http://ijssurgery.com/alerts 


\title{
Success Rate of Brace Treatment for Juvenile-Onset Idiopathic Scoliosis up to Skeletal Maturity
}

\author{
TAHER BABAEE, PhD,${ }^{1}$ MOJTABA KAMYAB, $\mathrm{PhD},{ }^{1}$ MOHAMMAD SALEH GANJAVIAN, MD, ${ }^{2}$ \\ NAEIMEH ROUHANI, MSc, ${ }^{1}$ JAMES JARVIS, MD ${ }^{3}$ \\ ${ }^{I}$ Rehabilitation Research Center, Department of Orthotics and Prosthetics, School of Rehabilitation Sciences, Iran University of Medical Sciences, Tehran, Iran, \\ ${ }^{2}$ Department of Orthopaedic Surgery, Shafa Yahyaiian Hospital, Iran University of Medical Sciences, Tehran, Iran, ${ }^{3}$ Division of Orthopaedic Surgery, \\ University of Ottawa, Children's Hospital of Eastern Ontario, Ottawa, Canada
}

\begin{abstract}
Background: Natural history studies have reported that the progression rate of juvenile idiopathic scoliosis (JIS) curves larger than $20^{\circ}$ is high and tends to progress. The aim of this study was to investigate the outcome of bracing on JIS and to determine the prognostic factors on the success rate of brace treatment.

Methods: From March 1985 to February 2015, the clinical data of all JIS patients with referral age from 4 to 10 years who received brace treatment were reviewed. Those patients with a prebrace Cobb angle $>20^{\circ}$ and a Risser sign of 0 to 2 were included and followed up a minimum of 2 years after discontinuation of the brace or time of spinal fusion. The Cobb angle was recorded at the time of diagnosis, before initiation of bracing, weaning time, brace discontinuation, and final follow-up.

Results: From 297 patients with JIS, a total of 75 cases (18 boys, 57 girls) with an average curve magnitude of $31.9^{\circ}$ at the time of diagnosis met the inclusion criteria of the study. For successfully treated patients, the average best in-brace correction was $55 \%$ for Lenke I curves, $59 \%$ for Lenke II curves, $41 \%$ for Lenke III curves, and $62 \%$ for Lenke V curves. For a total of 27 patients $(36 \%)$, the brace treatment failed. Of these, 21 patients $(78 \%)$ reached spinal fusion, and curves of 6 patients $(22 \%)$ increased to $\geq 50^{\circ}$. The progression rate was highest in patients with Lenke type III curves $(67 \%)$, and also in those with a curve magnitude of $\geq 46^{\circ}(94 \%)$.
\end{abstract}

Conclusions: Brace treatment is an effective strategy for controlling the curve progression and avoiding spinal fusion in JIS.

Level of Evidence: 4

Other \& Special Categories

Keywords: juvenile idiopathic scoliosis, brace treatment, spinal fusion

\section{INTRODUCTION}

The unknown scoliosis that appears from 3 or 4 years to 10 years of age is called juvenile idiopathic scoliosis (JIS) ${ }^{1-6}$ and is observed in $8 \%$ to $21 \%$ of all types of idiopathic scoliosis (IS) cases. ${ }^{2,7,8}$ The male to female ratio of JIS varies across the ages of manifestation and ranges ${ }^{2,9}$ from 1:1.6 to 1:4.4. Natural history studies have reported that the progression rate of JIS is higher than that of adolescent idiopathic scoliosis. ${ }^{10}$

Observation and bracing are the most common types of nonsurgical treatment for JIS patients. Precise observation at intervals of every 4, 6, 9, and 12 months is the strategy chosen for patients with a Cobb angle of less than $20^{\circ}{ }^{5}$ Bracing is indicated for those patients with progressive curves larger than $20^{\circ}$. However, the effectiveness of bracing for JIS is controversial.
Rates of success with the brace treatment for JIS were reported $^{1-3,11-15}$ as $12.5 \%$ to $95 \%$; due to the dissimilarity of the research method, follow-up duration, and heterogeneity of the patients, the results of these studies are not conclusive. Therefore, the aim of the present study was to investigate the long-term results of bracing in JIS up to 2 years after completion of brace treatment or spinal fusion. Evaluation of prognostic factors that can be involved in the effectiveness of bracing such as initial curve magnitude, ${ }^{16}$ curve type, ${ }^{15}$ best in-brace correction (BIBC), ${ }^{17}$ and brace compliance ${ }^{18}$ has been another goal of this study.

\section{MATERIAL AND METHODS}

\section{Patients}

This was a case series retrospective chart review study conducted in the senior author's (M.S.G.) 
spine clinic. Before initiation of the study, ethics approval was obtained from the ethics committee of Iran University of Medical Sciences. From March 1985 to February 2015, the clinical data of all patients with JIS who received brace treatment were reviewed. The inclusion criteria of the study were as follows: referral age from 4 to 10 years, prebrace Cobb angle $>20^{\circ}$, Risser sign 0 to 2 at initiation of bracing, followed up to the end of skeletal maturity on the basis of a Risser sign $>4$, completion of brace treatment, no history of prior surgical treatment, a minimum of 2 years of follow-up after completion of brace treatment, and having complete x-ray data from initial visit until skeletal maturity or surgical intervention. All patients with missing records or radiographs during brace treatment and follow-up, those who discontinued brace treatment before skeletal maturity, and the patients under treatment as well as skeletally immature patients were excluded.

All radiographical parameters were measured and recorded by the senior author (M.S.G.) using 1 protractor to minimize interobserver variability. ${ }^{19}$ In addition, all clinical records were surveyed by the first author (T.B.).

The primary goals of bracing for JIS are halting the curve progression and delaying surgical intervention during the growth period of patients. Therefore, for JIS patients with a curve severity of $>45^{\circ}$, brace treatment is often prescribed to lessen the risk of rapid curve progression and to delay spinal fusion.

\section{Brace Treatment}

During chart review the following information was recorded: (1) gender, (2) age (at baseline, before bracing, menarche, before surgery, weaning from brace, discontinuation of brace, and skeletal maturity), (3) scoliosis Cobb angle (at baseline, before bracing, best in-brace, before surgery, weaning from brace, discontinuation of brace, and final followup), (4) brace wearing time, (5) brace type, and (6) brace compliance. Best in-brace correction (BIBC) was determined according to the description of Jarvis et al. ${ }^{20}$ During the brace treatment and at each routine visit of the patients (at intervals of 4 to 6 months), the physician recorded the brace compliance via asking the patients and the appearance of the brace. The patients were classified into 2 groups based on compliance rate: (1) full compliance (those who had been wearing the brace for $>20$ hours a day) and (2) partial compliance (those who had been wearing the brace for $<20$ hours a day).

The Lenke classification system was used to explain the type of the curve. ${ }^{5}$ Before bracing, Cobb angles were classified into 3 groups $\left(\leq 29^{\circ}, 30^{\circ}\right.$ to $45^{\circ}$, and $\geq 46^{\circ}$ ) to evaluate the outcome of bracing based on curve type and curve magnitude. In all patients, the largest curve at baseline was considered for statistical analysis. The bracing was considered successful if the curve magnitude at final follow-up measured $<50^{\circ} .^{21}$

To report this case series, we used preferred reporting of case series in surgery guidelines.

\section{Statistical Methods}

Statistical calculations were performed using SPSS software, version 17 (SPSS Inc, Chicago IL), and GraphPad Prism software for Windows, version 8 (GraphPad Prism Software Inc, San Diego, CA). To describe the characteristics of the patients, descriptive statistics (mean, standard deviation, and range) were used. For nominal variables, the $\chi^{2}$ test and for continuous statistics the independent sample $t$ test were run. The analyses were performed between the success/stable and progression/surgery groups. A Friedman test was applied to evaluate the changes in the curve size across the different time periods of brace treatment. A $P$ value of less than .05 was considered statistically significant.

\section{RESULTS}

\section{Patients}

From 297 patients with JIS, 222 patients were excluded. Of these, 23 patients were treated by physical therapy, 12 patients had surgery, 11 patients did not have IS, 16 patients were still under treatment, and 43 patients were lost to final followup, and 117 patients discontinued the bracing before skeletal maturity (Figure 1). Finally, a total of 75 patients (18 boys, 57 girls) with a mean age of $6.94 \pm$ 1.86 years at the time of diagnosis met the inclusion criteria of the study. Of these, 66 patients $(88 \%)$ were treated with a Milwaukee brace, and the other 9 $(12 \%)$ were treated with Thoracolumbosacral orthosis. The girl to boy ratio was 3.1:1. Table 1 shows the baseline and prebrace characteristics of the patients.

\section{Bracing Outcome}

Characteristics of the patients at different stages of brace treatment between the success/stable and 


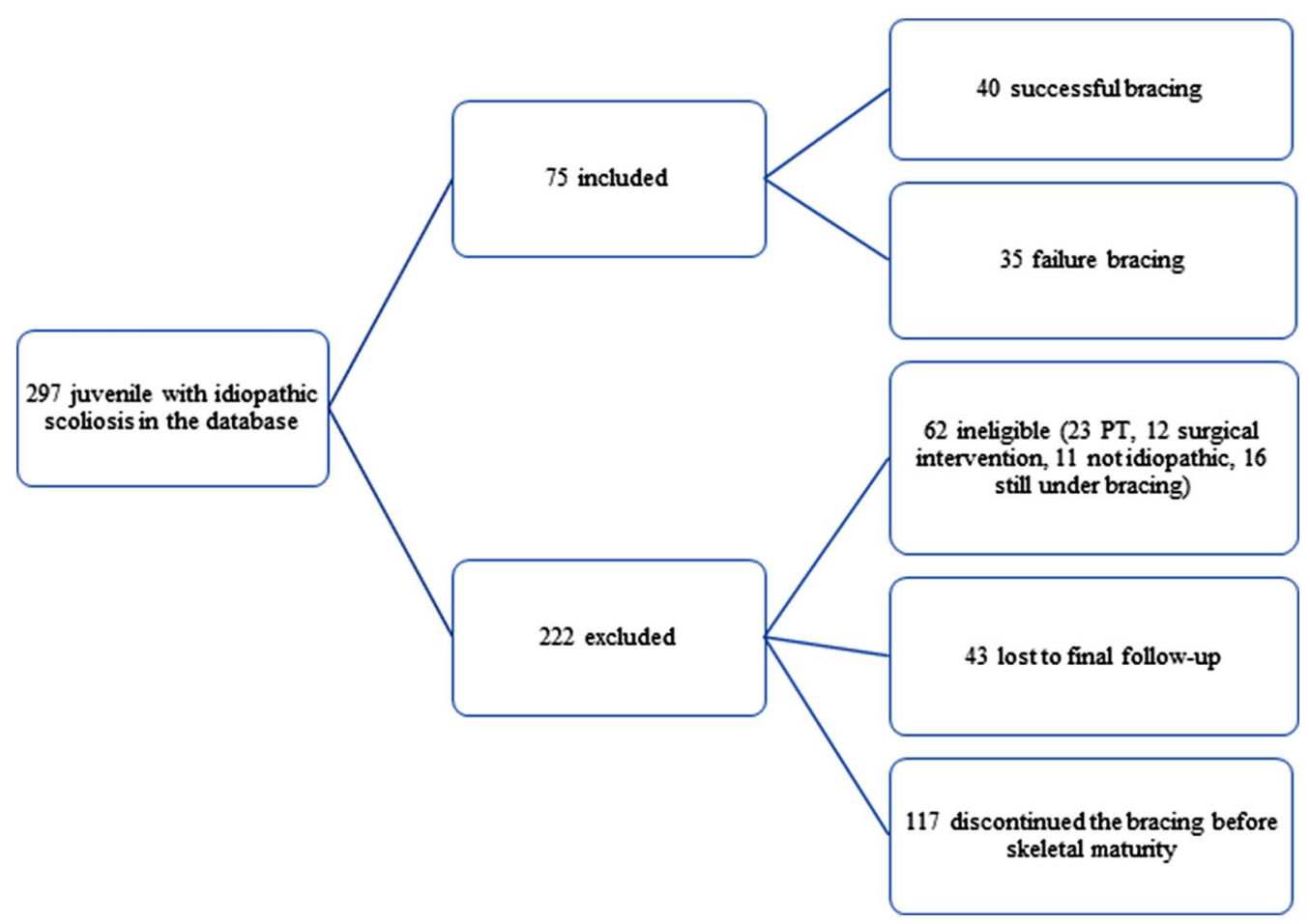

Figure 1. Flowchart describing the eligible and ineligible patients in the present study.

progression/surgery groups are reported in Table 2. In total, bracing was successful for 48 patients $(64 \%)$. Among successfully treated patients with JIS, 25 patients had been braced at their juvenile period and 23 at adolescence. The mean age, thoracic kyphosis angle between $\mathrm{T}_{2}$ and $\mathrm{T}_{12}$, scoliosis Cobb angle, Risser sign at initiation of bracing, follow-up duration, and brace wearing time of these patients are outlined in Table 3 . The overall effectiveness of brace treatment was $88 \%(24 / 27)$ when bracing was initiated during adolescence, which significantly decreased to $54 \%(26 / 48)$ when bracing was initiated during the juvenile period $(P=$ $.01)$.

Figure 2 summarizes the Cobb angle values across 5 time periods (baseline, before bracing, weaning, brace discontinuation, and final followup). The results of the Friedman test showed that there was a significant difference in Cobb angle

Table 1. Characteristics of the entire patient sample at baseline and before initiation of bracing.

\begin{tabular}{lcc}
\hline Parameters & $\begin{array}{c}\text { At baseline } \\
\text { Mean } \pm \text { SD (range) }\end{array}$ & $\begin{array}{c}\text { At initiation of bracing } \\
\text { Mean } \pm \text { SD (range) }\end{array}$ \\
\hline $\begin{array}{l}\text { Age, y } \\
\text { Scoliosis Cobb } \\
\quad \text { angle, }\end{array}$ & $6.94 \pm 1.86(4-9)$ & $8.62 \pm 2.60(4-13)$ \\
$\begin{array}{l}\text { Kyphosis Cobb } \\
\text { angle, }{ }^{\circ}\end{array}$ & $48.40 \pm 12.25(30-86)$ & $49.81 \pm 12.23(30-86)$ \\
\hline
\end{tabular}

values across these 5 time periods $\left(\chi^{2}=57.59, P\right.$ $<.001)$. Survey of the median values indicated a decrease in Cobb angle values from initiation of bracing $\left(\right.$ median $\left.=28^{\circ}\right)$ to weaning $\left(\right.$ median $\left.=25^{\circ}\right)$. However, the Cobb angle values increased from weaning to discontinuation of bracing (median $=$ $30^{\circ}$ ) and showed a further increase at final follow-up $\left(\right.$ median $\left.=35^{\circ}\right)$.

\section{Brace Compliance}

There was a significant difference in terms of adherence to the brace between the success/stable and progression/surgery groups $(P=.008)$ (Figure 3$)$.

Table 2. The mean age, Risser sign, and scoliosis Cobb angles at different stages of brace treatment between the success/stable and progression/surgery groups $(n=75)$.

\begin{tabular}{|c|c|c|c|}
\hline Parameters & $\begin{array}{c}\text { Success/ } \\
\text { stable } \\
(n=48)\end{array}$ & $\begin{array}{c}\text { Progression/ } \\
\text { surgery } \\
(n=27)\end{array}$ & $\boldsymbol{P}$ \\
\hline Age at baseline, $\mathrm{y}$ & $6.89 \pm 1.81$ & $7.03 \pm 1.99$ & .75 \\
\hline Age at initiation of bracing, $y$ & $9.16 \pm 2.74$ & $7.66 \pm 2.05$ & .01 \\
\hline $\begin{array}{l}\text { Risser sign at initiation } \\
\text { of bracing }\end{array}$ & $0.69 \pm 0.85$ & $0.15 \pm 0.36$ & $<.001$ \\
\hline Cobb angle at baseline, ${ }^{\circ a}$ & $25.39 \pm 9.10$ & $43.59 \pm 14.27$ & $<.001$ \\
\hline $\begin{array}{l}\text { Cobb angle at initiation } \\
\text { of bracing, }\end{array}$ & $29.93 \pm 7.62$ & $45.29 \pm 12.53$ & $<.001$ \\
\hline $\begin{array}{l}\text { Cobb angle at brace } \\
\text { discontinue }^{\mathrm{b}}\end{array}$ & $31.22 \pm 9.62$ & $63.11 \pm 13.93$ & $<.001$ \\
\hline
\end{tabular}

${ }^{\mathrm{a}}$ Largest curve was measured.

${ }^{\mathrm{b}}$ For surgery group, preoperative Cobb angle was considered. 
Table 3. Results of the patients with stable/improved curve $(n=48)$.

\begin{tabular}{|c|c|c|c|c|c|}
\hline \multirow[b]{2}{*}{ Parameters } & \multicolumn{2}{|c|}{ Juveniles ( $\mathrm{n}=25,5$ boys/20 girls) } & \multicolumn{2}{|c|}{ Adolescents ( $n=23,6$ boys $/ 17$ girls) } & \multirow[b]{2}{*}{$P$} \\
\hline & Mean \pm SD & Range & Mean \pm SD & Range & \\
\hline \multicolumn{6}{|l|}{ Age, $y$} \\
\hline Baseline & $6.16 \pm 1.72$ & $4-9$ & $7.69 \pm 1.57$ & 4-9 & .002 \\
\hline Initiation of bracing & $6.96 \pm 1.76$ & $4-9$ & $11.56 \pm 1.07$ & $10-13$ & $<.001$ \\
\hline Menarche & $11.96 \pm 1.17$ & $9-15$ & $11.86 \pm 0.88$ & $10-13$ & .79 \\
\hline Weaning & $14.28 \pm 1.42$ & $12-17$ & $14.86 \pm 1.28$ & $13-17$ & .14 \\
\hline Skeletal maturity & $16.28 \pm 1.17$ & $14-18$ & $16.34 \pm 1.22$ & $14-18$ & .75 \\
\hline \multicolumn{6}{|l|}{ Scoliosis Cobb angle, ${ }^{\circ}$} \\
\hline Baseline & $28.44 \pm 10.68$ & $13-45$ & $22.08 \pm 5.55$ & $14-33$ & .01 \\
\hline Initiation of bracing & $32.60 \pm 8.91$ & $20-50$ & $27.04 \pm 4.55$ & $20-35$ & $<.001$ \\
\hline Initiation of weaning & $27.04 \pm 12.34$ & $8-54$ & $23.17 \pm 8.10$ & $10-40$ & .21 \\
\hline Brace discontinue & $34.04 \pm 9.35$ & $12-48$ & $28.17 \pm 9.15$ & $10-45$ & .03 \\
\hline Final follow-up & $37.56 \pm 9.60$ & $14-48$ & $30.95 \pm 9.73$ & $12-47$ & .02 \\
\hline \multicolumn{6}{|l|}{ Kyphosis Cobb angle, $^{\circ}$} \\
\hline Baseline & $50.24 \pm 14.85$ & $30-86$ & $46.26 \pm 8.82$ & $30-60$ & .27 \\
\hline Initiation of bracing & $52.40 \pm 14.84$ & $30-86$ & $47.21 \pm 8.40$ & $30-60$ & .14 \\
\hline Initiation of weaning & $36.24 \pm 7.17$ & $25-65$ & $33.39 \pm 6.31$ & $25-45$ & .14 \\
\hline Brace discontinue & $39.68 \pm 8.36$ & $25-65$ & $36.07 \pm 6.04$ & $25-46$ & .14 \\
\hline Final follow-up & $41.36 \pm 7.67$ & $28-58$ & $39.21 \pm 9.26$ & $25-65$ & 0.19 \\
\hline Brace wearing time, y & $8.72 \pm 2.55$ & $(5-13)$ & $4.52 \pm 1.37$ & $2-8$ & $<.001$ \\
\hline Follow-up duration, mo & $26.00 \pm 8.39$ & $16-60$ & $29.17 \pm 20.56$ & $18-120$ & .22 \\
\hline Prebrace Risser sign & $0.08 \pm 0.40$ & $0-2$ & $1.34 \pm 0.71$ & $0-2$ & $<.001$ \\
\hline
\end{tabular}

In the successfully treated group, 37 patients $(77 \%)$ had full compliance and 11 had partial compliance $(23 \%)$. On the other hand, in the progression/surgery group, 12 patients (44\%) had full compliance and 15 had partial compliance $(56 \%)$.

\section{Effect of Curve Type and Curve Magnitude}

Impact of prebrace curve type and curve magnitude on the outcome of bracing is presented in Table 4. As expected, the progression rate was highest in

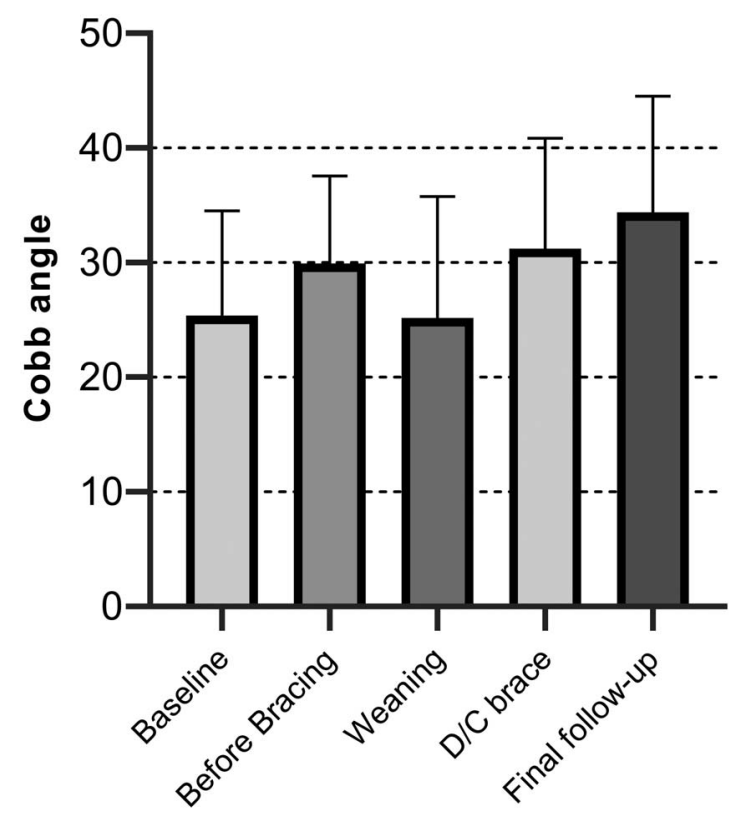

Figure 2. The Cobb angle values across 5 time periods of brace treatment (baseline, before bracing, weaning, brace discontinuation, and final follow-up). patients with Lenke type III and lowest in Lenke type $\mathrm{V}$. Before initiation of bracing, 28 patients had a Cobb angle of $29^{\circ}$ or less $\left(24.28^{\circ} \pm 2.60^{\circ}\right), 31$ patients had a Cobb angle of $30^{\circ}$ to $45^{\circ}\left(35.67^{\circ} \pm\right.$ $\left.5.00^{\circ}\right)$, and the other 16 patients showed a large Cobb angle of $>46^{\circ}$ or more $\left(54.62^{\circ} \pm 6.27^{\circ} ; P<\right.$ $.001)$. The progression rate was very high in patients with a curve magnitude of $\geq 46^{\circ}(94 \%)$.

The average BIBC was $57 \%(6 \%-100 \%)$. However, patients with different curve type revealed a different BIBC. The average BIBC was $55 \%(6 \%-$ $100 \%)$ for Lenke type I curves, 59\% (26\%-100\%) for Lenke type II curves, $41 \%(14 \%-67 \%)$ for Lenke type III curves, and 62\% $(25 \%-100 \%)$ for Lenke type $\mathrm{V}$ curves. The results indicated that the

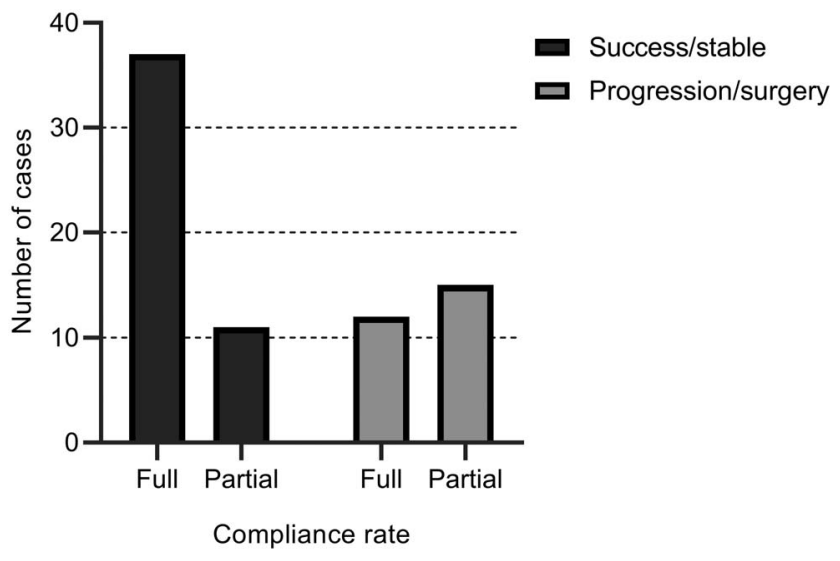

Figure 3. Brace compliance between the success/stable and progression/ surgery groups. 
Table 4. Impact of prebrace curve type and curve magnitude on effectiveness of bracing.

\begin{tabular}{lrrrr}
\hline & $\begin{array}{c}\text { Success/ } \\
\text { stable, } \\
\text { n/N (\%) }\end{array}$ & $\begin{array}{c}\text { Progression/ } \\
\text { surgery, } \\
\text { n/N (\%) }\end{array}$ & Cramer V $\mathbf{~}^{\mathbf{2}}$ & $\boldsymbol{P}$ \\
\hline Curve type & & & & \\
$\quad$ Lenke I & $17 / 25(68)$ & $8 / 25(32)$ & .36 & .01 \\
Lenke II & $4 / 7(57)$ & $3 / 7(43)$ & & \\
Lenke III & $6 / 18(33)$ & $12 / 18(67)$ & & \\
Lenke V & $21 / 25(84)$ & $4 / 25(16)$ & & \\
Curve magnitude & & & \\
$\leq 29^{\circ}$ & $25 / 28(89)$ & $3 / 28(11)$ & .59 & $<.001$ \\
$30^{\circ}-45^{\circ}$ & $22 / 31(71)$ & $9 / 31(29)$ & & \\
$\geq 46^{\circ}$ & $1 / 16(6)$ & $15 / 16(94)$ & & \\
\hline
\end{tabular}

${ }^{\mathrm{a}}$ Effect size for $\chi^{2}$ test.

Lenke type III curve is a prognostic factor for curve progression and spinal fusion.

\section{Surgery}

For a total of 27 patients $(36 \%)$ the brace treatment failed. Of these, 21 patients $(78 \%)$ underwent spinal fusion and the curves of 6 patients $(22 \%)$ increased to $\geq 50^{\circ}$. Considering the clinical characteristics of JIS patients such as age, skeletal maturity, functional status, spinal height, and patients' and parents' preferences, the decision for surgical procedure may be difficult and complex. Nevertheless, the routine suggestion ${ }^{15}$ for spinal fusion in JIS patients is presence of a curve size $>50^{\circ}$. At initiation of bracing, the average Cobb angle of the these patients was $46.90^{\circ} \pm 12.00^{\circ}\left(25^{\circ}-\right.$ $\left.70^{\circ}\right)$. Before surgery, the average age was $13.42 \pm$ 1.39 years (10-15 years), with an average Cobb angle of $66.52^{\circ} \pm 13.57^{\circ}\left(45^{\circ}-95^{\circ}\right)$. Finally, the rate of surgery was $48 \%$ (10 patients) in Lenke type III curves, $28.5 \%$ (6 patients) in Lenke type I curves, $14 \%$ (3 patients) in Lenke type $\mathrm{V}$ curves, and 9.5\% (2 patients) in Lenke type II curves.

\section{DISCUSSION}

In JIS patients, the risk of curve progression is greater than in adolescent idiopathic scoliosis because the time span between initiation of deformity and skeletal maturity is very long. Therefore, for patients with progressive curves, consideration of brace management at manifestation of the deformity may significantly affect the final results. The present study was conducted with the aim of investigating the outcome of bracing in JIS patients and determining the influential factors on the success rate of brace treatment. The results showed that the success rate of bracing was $64 \%$.
To the best of our knowledge, in the literature overall, 12 English language studies exist that have reported the results of brace treatment for JIS. ${ }^{1-3,9,11-15,20,22,23}$ Of these, only 5 studies had sample sizes of larger than 50 patients. $2,11,12,15,24$ The lowest success rate of bracing in JIS patients was reported in the Robinson and McMaster case series, ${ }^{2}$ where in spite of early diagnosis of deformity, brace treatment was initiated only for those with a curve magnitude higher than $30^{\circ}$ (88 cases). In this study, the success rate was reported as $12.5 \%$ and the patients were followed up until skeletal maturity or spinal fusion. On the other hand, the highest success rate of bracing in JIS (94\%) was reported by Aulisa et al, ${ }^{11}$ who conducted their study on 113 patients. In the study of Khoshbin et al, ${ }^{15}$ of the 88 cases with JIS, the overall success rate with bracing was $28 \%$. Of the 125 patients in Harshavardhana and Lonstein's study, ${ }^{24}$ the reported success rate was $41 \%$. Furthermore, in 5 studies, the follow-up duration was short, and not all patients were examined until skeletal maturity. ${ }^{3,9,13,14,22}$ In the study by Coillard et $\mathrm{al}^{12}$ of 150 JIS patients undergoing the SpineCor brace treatment, only 67 patients were followed up until the end of skeletal maturity. Tolo et $\mathrm{al}^{3}$ conducted a study on 42 JIS patients, reporting the success rate of bracing as $81 \%$. However, in this study, the follow-up duration was short, and only 4 patients were followed up until the end of skeletal maturity. The studies ${ }^{25}$ on patients with adolescent idiopathic scoliosis showed that after discontinuation of the brace treatment, nearly one third of the curves increased to higher than $5^{\circ}$. In the successfully treated patients of the present study, from initiation of weaning time to final follow-up, $63 \%$ of the curves had progressed to $>5^{\circ}$.

In the present study we identified the prognostic factors in effectiveness of bracing such as BIBC, brace compliance, curve size, and curve type at initiation of bracing. The results indicated that the surgical rate in the patients with a prebrace Cobb angle $<29^{\circ}$ was very low $(11 \%)$. However, for patients with a curve magnitude $>46^{\circ}$, the rate of curve progression reached $94 \%$. Therefore, bracing has a limited capacity to control the curve progression for JIS patients with Cobb angles $>46^{\circ}$. The curve magnitude at initiation of bracing and surgical rate in patients who had braced during adolescents was significantly lower as compared with those who were braced during the juvenile period. These results 
are in line with the findings of Khoshbin et $\mathrm{al}^{15}$ and Harshavardhana and Lonstein. ${ }^{24}$

The mean BIBC in the present study was $57 \%$; the maximum value was associated with patients with Lenke type $\mathrm{V}$ curve, and the minimum was associated with patients with Lenke type III curve. Thus, Lenke type III curve is a prognostic risk factor for progression of the curve and spinal fusion. ${ }^{15,26}$ In the present study, of 18 patients with Lenke type III curve, 10 patients had partial compliance and 8 had full compliance. However, there was no statistically significant difference in their compliance rate. Therefore, the lower success rate of bracing in patients with Lenke type III curve might be associated with the rigidity of the curve or the brace fitting. Previous studies have suggested that an increase in flexibility across the scoliosis curve and adjustment of the pressure pads of the brace at shorter intervals will decrease the risk of curve progression in patients with adolescent idiopathic scoliosis. ${ }^{27-29}$ Further research is required to evaluate these factors on JIS patients.

In the present study, brace compliance was assessed subjectively (reported by patients) and through appearance of the brace. The results showed that the compliance rate is associated with the outcome of brace treatment. In the success/ stable group, compliance rate was significantly higher than in the progression/surgery group. These findings are consistent with the results of previous studies on JIS patients. ${ }^{15,18}$ Today, to measure the compliance objectively, reliable temperature or pressure data loggers are used, which offer researchers more accurate information on adherence of patients to the brace..$^{30,31}$

There are no standardized criteria for evaluating the brace effectiveness on JIS. Recently, Harshavardhana and Lonstein ${ }^{24}$ published the results of their series on 125 juveniles with idiopathic scoliosis who were followed up until the end of skeletal maturity. In this study, the success rate of brace treatment according to inclusion criteria of the Scoliosis Research Society (SRS) Committee was reported as $41 \%$. In the present study, the success of brace treatment based on the criteria of the Bracing in Adolescent Idiopathic Scoliosis Trial (BrAIST) was $64 \%$. However, if the success rate had been considered on the basis of SRS, ${ }^{32}$ it would have been $54 \%$. The next step for SRS is establishing uniform criteria for subsequent studies on the effectiveness of bracing in JIS patients.
The present study had some limitations, however. First, because $54 \%$ of patients in our database were excluded from the study due to having been lost to final follow-up and discontinuation of bracing before skeletal maturity, the results may suffer lack of generalizability. Nevertheless, this exclusion of patients is expected in a retrospective study covering a 30-year period. Second, given the retrospective nature of the study, our data were limited to the information available in the clinical records of the patients. Nevertheless, assessment and recording of the data of all patients were performed by 1 surgeon and based on a constant method. Also, all of the required information was extracted from the clinical files of patients by 1 author. Third, most of the patients were treated by the Milwaukee brace. However, it was not possible to compare the results of treatment based on the type of brace. Fourth, this was a single-center case series performed in the senior author's spine clinic, which may reduce the generalizability of the findings. However, this center is one of the largest spine clinics in Iran, where scoliosis patients were referred to from all cities and provinces. Fifth, due to the retrospective nature of the present study, evaluating patient records from 1986 to 2013, measuring the brace wear compliance objectively was not feasible. Lavelle ${ }^{33}$ first introduced the use of a data logger to objectively measure brace compliance in 1996. However, at each follow-up during brace treatment, the treating physician recorded the average hours of brace wearing by evaluating the appearance of the brace and asking the patients and parents. Sixth, the Cobb angle measurements were performed based on applying the classical Cobb method on total-spine posteroanterior x-ray films. Reports showed that some fault may have occurred as a result of measurement error and insufficient clarity of radiographs. ${ }^{34}$ However, measurement error can be reduced when all Cobb angles are recorded by 1 observer and using 1 protractor. ${ }^{19}$ Finally, due to absence of any control group, it was not possible to compare the results of bracing with the natural history of JIS.

\section{CONCLUSIONS}

Brace treatment is an effective strategy for controlling the curve progression and avoiding spinal fusion in JIS if the curves are spotted early. 
The initial curve magnitude, type of the curve, and degrees of in-brace correction are prognostic risk factors for progression of the curve and spinal fusion in JIS.

\section{REFERENCES}

1. Masso PD, Meeropol E, Lennon E. Juvenile-onset scoliosis followed up to adulthood: orthopaedic and functional outcomes. J Pediatr Orthop. 2002;22(3):279-284.

2. Robinson CM, McMaster MJ. Juvenile idiopathic scoliosis. Curve patterns and prognosis in one hundred and nine patients. J Bone Joint Surg Am. 1996;78(8):1140-1148.

3. Tolo VT, Gillespie R. The characteristics of juvenile idiopathic scoliosis and results of its treatment. J Bone Joint Surg Br. 1978;60-b(2):181-188.

4. Dobbs MB, Weinstein SL. Infantile and juvenile scoliosis. Orthop Clin North Am. 1999;30(3):331-341, vii.

5. Lenke LG, Dobbs MB. Management of juvenile idiopathic scoliosis. J Bone Joint Surg Am. 2007;89(suppl 1):55-63.

6. Stehbens WE, Cooper RL. Regression of juvenile idiopathic scoliosis. Exp Mol Pathol. 2003;74(3):326-335.

7. Riseborough EJ, Wynne-Davies R. A genetic survey of idiopathic scoliosis in Boston, Massachusetts. J Bone Joint Surg Am. 1973;55(5):974-982.

8. Ponseti IV, Friedman B. Prognosis in idiopathic scoliosis. J Bone Joint Surg Am. 1950;32a(2):381-395.

9. Figueiredo UM, James JI. Juvenile idiopathic scoliosis. $J$ Bone Joint Surg Br. 1981;63-b(1):61-66.

10. Di Felice F, Zaina F, Donzelli S, Negrini S. The natural history of idiopathic scoliosis during growth: a meta-analysis. Am J Phys Med Rehabil. 2018;97(5):346-356.

11. Aulisa AG, Guzzanti V, Marzetti E, Giordano M, Falciglia F, Aulisa L. Brace treatment in juvenile idiopathic scoliosis: a prospective study in accordance with the SRS criteria for bracing studies-SOSORT Award 2013 winner. Scoliosis. 2014;9:3.

12. Coillard C, Circo AB, Rivard CH. SpineCor treatment for juvenile idiopathic scoliosis: SOSORT Award 2010 winner. Scoliosis. 2010;5:25.

13. Mannherz RE, Betz RR, Clancy M, Steel HH. Juvenile idiopathic scoliosis followed to skeletal maturity. Spine (Phila Pa 1976). 1988;13(10):1087-1090.

14. Kahanovitz N, Levine DB, Lardone J. The part-time Milwaukee brace treatment of juvenile idiopathic scoliosis. Longterm follow-up. Clin Orthop Relat Res. 1982;1982(167):145-151.

15. Khoshbin A, Caspi L, Law PW, et al. Outcomes of bracing in juvenile idiopathic scoliosis until skeletal maturity or surgery. Spine (Phila Pa 1976). 2015;40(1):50-55.

16. Lang C, Sui W, Di M, et al. Factors that influence inbrace correction in patients with adolescent idiopathic scoliosis. World Neurosurg. 2019;123: e597-e603.doi:10.1016/j.wneu. 2018.11.228

17. $\mathrm{Xu} \mathrm{L}$, Yang $\mathrm{X}$, Wang $\mathrm{Y}$, et al. Brace treatment in adolescent idiopathic scoliosis patients with curve between $40^{\circ}$ and $45^{\circ}$ : Effectiveness and related factors. World Neurosurg. 2019;126: e901-e906. doi:0.1016/j.wneu.2019.03.008

18. Brox JI, Lange JE, Gunderson RB, Steen H. Good brace compliance reduced curve progression and surgical rates in patients with idiopathic scoliosis. Eur Spine J. 2012;21(10):19571963.

19. Morrissy RT, Goldsmith GS, Hall EC, Kehl D, Cowie GH. Measurement of the Cobb angle on radiographs of patients who have scoliosis. Evaluation of intrinsic error. $J$ Bone Joint Surg Am. 1990;72(3):320-327.

20. Jarvis J, Garbedian S, Swamy G. Juvenile idiopathic scoliosis: the effectiveness of part-time bracing. Spine (Phila Pa 1976). 2008;33(10):1074-1078.

21. Weinstein SL, Dolan LA, Wright JG, Dobbs MB. Effects of bracing in adolescents with idiopathic scoliosis. $N$ Engl J Med. 2013;369(16):1512-1521.

22. van Hessem L, Schimmel JJ, Graat HC, de Kleuver M. Effective nonoperative treatment in juvenile idiopathic scoliosis. J Pediatr Orthop B. 2014;23(5):454-460.

23. Fusco C, Donzelli S, Lusini M, Salvatore M, Zaina F, Negrini S. Low rate of surgery in juvenile idiopathic scoliosis treated with a complete and tailored conservative approach: end-growth results from a retrospective cohort. Scoliosis. 2014;9:12.

24. Harshavardhana NS, Lonstein JE. Results of bracing for juvenile idiopathic scoliosis Spine Deformity. 2018;6(3):201206.

25. Abel MF. Brace success as related to curve type, compliance, and maturity in adolescents with idiopathic scoliosis: commentary on an article by Rachel M. Thompson, MD, et al: "Brace Success Is Related to Curve Type in Patients With Adolescent Idiopathic Scoliosis." J Bone Joint Surg Am. 2017;99(11):e59.

26. Thompson RM, Hubbard EW, Jo CH, Virostek D, Karol LA. Brace success is related to curve type in patients with adolescent idiopathic scoliosis. J Bone Joint Surg Am. 2017;99(11):923-928.

27. Hedayati Z, Ahmadi A, Kamyab M, Babaee T, Ganjavian MS. Effect of group exercising and adjusting the brace at shorter intervals on Cobb angle and quality of life of patients with idiopathic scoliosis. Am J Phys Med Rehabil. 2018;97(2):104-109.

28. Ohrt-Nissen S, Hallager DW, Gehrchen M, Dahl B. Flexibility predicts curve progression in providence nighttime bracing of patients with adolescent idiopathic scoliosis. Spine (Phila Pa 1976). 2016;41(22):1724-1730.

29. Cheung JPY, Yiu KKL, Vidyadhara S, Chan PPY, Cheung PWH, Mak KC. Predictability of supine radiographs for determining in-brace correction for adolescent idiopathic scoliosis. Spine (Phila Pa 1976). 2017;43(14):971-976.

30. Havey R, Gavin T, Patwardhan A, et al. A reliable and accurate method for measuring orthosis wearing time. Spine (Phila Pa 1976). 2002;27(2):211-214.

31. Benish BM, Smith KJ, Schwartz MH. Validation of a miniature thermochron for monitoring thoracolumbosacral orthosis wear time. Spine (Phila Pa 1976). 2012;37(4):309-315.

32. Richards BS, Bernstein RM, D'Amato CR, Thompson GH. Standardization of criteria for adolescent idiopathic scoliosis brace studies: SRS Committee on Bracing and Nonoperative Management. Spine (Phila Pa 1976). 2005;30(18):2068-2075, discussion 76-77.

33. Lavelle J. An assessment of brace compliance in adolescent idiopathic scoliosis using a new brace timer. $J$ Bone Joint Surg Br. 1996;78B(suppl 2):162.

34. Malfair D, Flemming AK, Dvorak MF, et al. 
Radiographic evaluation of scoliosis. AJR Am J Roentgenol. 2010;194(suppl 3):S8-S22.

Disclosures and COI: This research was supported by grant No. 32-33718 from the Rehabilitation Research Center of Iran University of Medical Sciences. The authors report no conflicts of interest.

Corresponding Author: Taher Babaee, $\mathrm{PhD}$, Rehabilitation Research Center, Department of Orthotics and Prosthetics, School of Rehabilitation Sciences, Iran University of Medical Sciences,
Madadkaran Avenue, Shahnazari St, Madar Square, Mirdamad Blvd, Tehran, Iran. Phone: +98 2122220947 (ext 244); Fax: +98 212222 0946; Email: babaee.t@iums.ac.

Published 11 November 2020

This manuscript is generously published free of charge by ISASS, the International Society for the Advancement of Spine Surgery. Copyright (C) 2020 ISASS. To see more or order reprints or permissions, see http://ijssurgery.com. 